Original Research Article

\title{
Drug utilisation and self medication pattern of anti-fungal drugs in dermatology outpatient department of a tertiary care hospital
}

\author{
Pooja Deb $^{1}$, Ipseeta Mohanty ${ }^{1 *}$, Indu Slathia ${ }^{1}$, Vandana Verma $^{2}$
}

\begin{abstract}
${ }^{1}$ Department of Pharmacology, ${ }^{2}$ Department of Dermatology, MGM Medical College, Navi Mumbai, Maharashtra, India
\end{abstract}

Received: 23 June 2017

Accepted: 24 July 2017

\section{*Correspondence to:}

Dr. Ipseeta Mohanty,

Email: ipseetamohanty@ yahoo.co.in

Copyright: () the author(s), publisher and licensee Medip Academy. This is an openaccess article distributed under the terms of the Creative Commons Attribution NonCommercial License, which permits unrestricted noncommercial use, distribution, and reproduction in any medium, provided the original work is properly cited.

\begin{abstract}
Background: Fungal infections have become increasingly prevalent. Selfmedication is a common health care practice to treat fungal diseases or for symptomatic relief. Because of self-medication drug-sensitive fungal pathogens have gradually developed resistance. Aims and objectives of the study was to define the pattern of antifungal drug use and self-medication pattern for common fungal infections of skin in dermatology outpatient.

Methods: The present study was an Observational, descriptive, cross sectional study conducted at Dermatology OPD of MGM Medical College, Kamothe. All adult patients with fungal infections of the skin attending the Dermatology OPD were enrolled. A study performa was specifically designed to record information related to demographic, disease profile and medications prescribed.

Results: A total of 200 patient's prescriptions were analysed. Percentage of drugs prescribed by generic name was found to be $20.26 \%$, Percentage of drugs prescribed from National Essential Drug List 2015 was found to be $79.74 \%$. There were no encounters with antibiotic and parenteral preparations. Only $5.16 \%$ of the drugs prescribed were fixed dose combination (FDC) as compared to $94.93 \%$ as Monotherapy. Most frequently prescribed anti-fungal agents were the azoles; amongst which Imidazoles (53.33\%) were the commonest. Most commonly prescribed individual antifungal was oral Terbinafine $(64.81 \%)$ and topical was Eberconazole (58.49\%). The dosage form most frequently encountered was Cream (92.45\%). The prevalence of self-medication for dermatological conditions among patients was $62.26 \%$. Most of the drugs for selfmedication were topical (creams) FDC of antifungal and steroids. Around $78 \%$ of the self-medication information was obtained from the chemists.

Conclusions: The study documented physician preference for Monotherapy than FDC. Prescribers need to be made aware for prescribing generic and essential drugs, thus ensuring rational utilization. They also need to counsel and discourage patients from self-medication.
\end{abstract}

Keywords: Drug utilization, Fungal, Generic, Monotherapy, Self-medication

\section{INTRODUCTION}

Fungal infections, both invasive and superficial, have become increasingly prevalent over the past few decades. ${ }^{1}$

The widespread use of antibiotics has contributed to the growing infection rate as fungal infections are known to occur after antibiotic therapy, which has the effect of killing the beneficial bacteria that normally suppress fungi. $^{2}$
The most common organism implicated in fungal infections is the ubiquitous Candida, which is found in the human digestive tract, mouth, and genital region. ${ }^{3}$ These infections are typically divided into superficial, subcutaneous, and systemic mycoses according to the main site of clinical involvement. Topical antifungal agents are generally used as first-line therapy for uncomplicated, superficial, localized dermatomycoses, while systemic drugs are employed to treat more widespread cutaneous fungal infections, tinea-capitis, 
tinea-unguium (onychomycosis), as well as subcutaneous and systemic mycoses.

Patients can perceive some skin problems as irrelevant and self-limited, often engaging in self-medication before they seek medical care. Self-medication is becoming a common health care practice as people are becoming increasingly familiar with drugs and their brand names. ${ }^{4}$ Selfmedication behaviour varies significantly with a number of socio-economic factors. ${ }^{5}$ In these situations the use of topical drugs is frequent, often without apprehensions about adverse events such as bacterial resistance and masking of skin diseases. Although seen in clinical practice, there are few published studies that describe the process of self-medication in dermatology. ${ }^{5}$ The purpose of this study is to systematically review and describe the prevalence of self-medication in skin diseases, as well as the main pharmacological strategies used.

Drug utilization research or studies are the powerful exploratory tools to ascertain the role of drugs in the society which refers to the marketing, distribution, prescription and use of drugs with special emphasis on the medical, social and economic consequences. Periodic prescription audit in form of drug utilization study is a way to improve the quality of prescription and promote rational prescribing. ${ }^{6,7}$ The data regarding antifungal drug usage and self-medication pattern will provide meaningful information based on which interventions can be planned at the level of the patient, physician and Institute. Keeping these facts in consideration, the present study was planned in the in-outpatient department of Dermatology.

\section{METHODS}

This was an Open labelled, cross sectional, observational and prospective study conducted in the department of Dermatology from May 2016 to August 2016.

The study included patients attending dermatology department with cutaneous fungal infections. The participants were explained the purpose of the study and voluntary written informed consent was obtained. The study excluded patients with deep seated infections and the ones not willing for informed consent.

The demographic profile of the patients was noted. In addition, the prescribing indicators that were assessed were:

- Average number of drugs prescribed per patient,

- Percentage of utilization of the different classes of antifungal drugs,

- Percentage of encounters (prescription) with an antihistaminic prescribed,

- $\quad$ Percentage of encounters (prescription) with a topical antifungal prescribed,

- $\quad$ Percentage of encounters (prescription) with a topical antibiotic prescribed.
Self-medication Indices such as:

- Frequency of self medication,

- Drugs frequently self-medicated,

- Source of information for self medication were evaluated too.

Subsequently the details mentioned on the CRF were tabulated in the Excel form. The data that was collected; it was analysed and appropriate statistics were applied to obtain meaningful information.

\section{RESULTS}

\section{Demographic profile}

A total 200 prescriptions were analysed; out of which majority belonged to the age group of 18-30 years. Total number of males and females among all patients were 109 $(54.5 \%)$ and $91(45.5 \%)$ respectively.

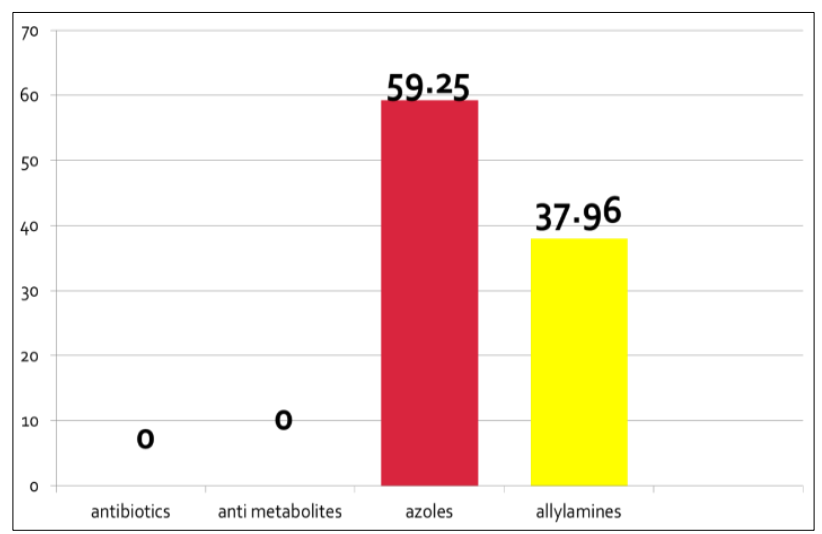

Figure 1: The antifungal drug group commonly used.

\section{Disease distribution}

The most commonly accounted disease were tinea infections; and tinea cutis, tineacorporis and onychomycosis being the commonest. 2.98 numbers of drugs were prescribed per prescription on an average.

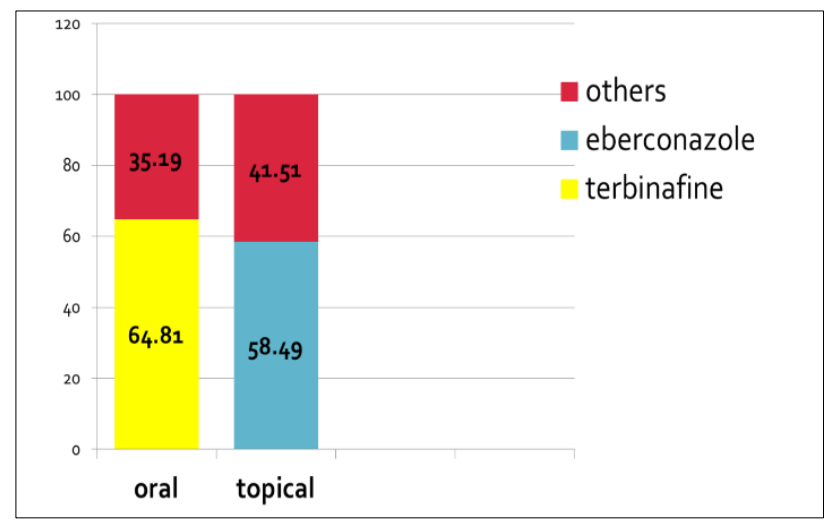

Figure 2: Most commonly used oral and topical antifungal drug. 


\section{Prescribing indices}

Average numbers of drugs prescribed per prescription was found to 2.98. Percentage of drugs prescribed by generic name was $20.26 \%$, Percentage of drugs prescribed from National Essential Drug List 2015 was found to be $62.34 \%$. Antibiotic and injections weren't prescribed at all. Only $5.16 \%$ of the drugs prescribed were fixed dose combination (FDC) as compared to $94.93 \%$ as Monotherapy.

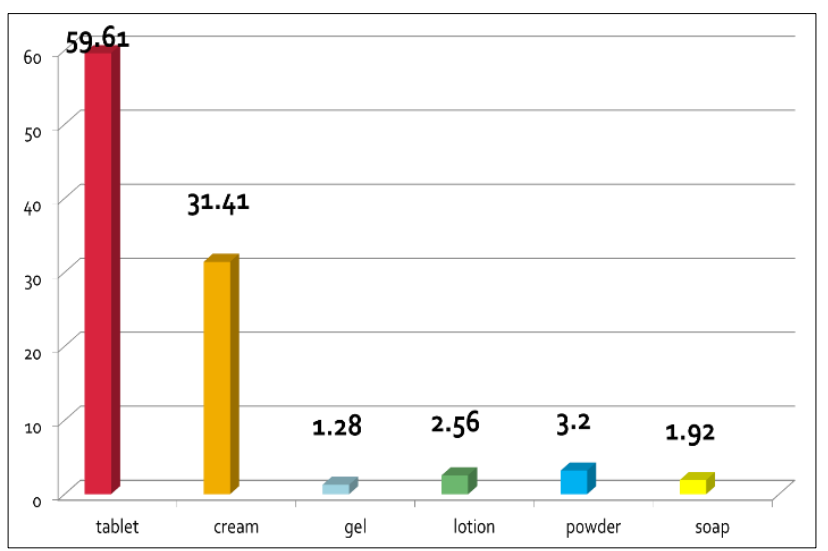

Figure 3: The dosage forms more frequently prescribed.

\section{Drug utilization pattern}

Most frequently prescribed anti-fungal agents were the azoles; amongst which Imidazoles (53.33\%) were the commonest. Most commonly prescribed individual antifungal was oral Terbinafine $(64.81 \%)$ and topical was Eberconazole (58.49\%). The dosage form most frequently encountered was tablet $(59.61 \%){ }^{8}$

\section{Self medication pattern}

The prevalence of self-medication for dermatological conditions among patients was $62.26 \%$. Most of the drugs for self-medication were topical (creams) FDC of antifungal and steroids. ${ }^{9}$ Around $78 \%$ of the selfmedication information was obtained from the chemists.

\section{DISCUSSION}

Skin diseases are common and cause a huge disease burden globally. Collectively skin disease is the $18^{\text {th }}$ leading cause of health burden worldwide and it was $4^{\text {th }}$ leading cause of nonfatal health burden in 2010 globally. Fungal infections are more common today than ever before and its prevalence in India is rising. ${ }^{10}$ The skin disorders have serious detrimental effect on quality of life of the general population by increasing the suffering in terms of physical, social, psychological as well as it increases financial burden as most of the skin diseases are chronic and requires longer duration of treatment. ${ }^{11}$
As per WHO, Drug utilization studies are tools that deals with prescription pattern of drugs and helps in the understanding of prescription trend as well as the quality of prescription in terms of rationality, drug interactions and financial burden of disease. These studies have a favourable impact on improving the standards of treatment and identify the problems related to polypharmacy, drugdrug interaction and adverse drug reactions. Periodic auditing of prescriptions in form of drug utilization studies are important tool to enhance the therapeutic efficacy, to minimize the adverse effect, to optimize the cost of the treatment and to provide useful feedback to the clinician.

Another menace that needs to be addressed is the prevalence of antifungal self-medication among patients. Non-prescription use of antifungal drugs is associated with the risk of inappropriate drug use which predisposes patients to drug interactions, masking symptoms of underlying disease and development of microbial resistance. ${ }^{5,9}$ Therefore to define the pattern of antifungal drug use and self- medication pattern for common fungal infections of skin in dermatology outpatient the present study was designed. Results will help to identify gaps in prescription patterns that need to be addressed in order to promote rational uses of medicines and discourage selfmedication practices.

Prescription indices showed the inclination towards prescribing drugs from their brand names was more prevalent. Only $20.26 \%$ of drugs prescribed were generic, which compares well with most of the studies. $62.24 \%$ of drugs prescribed were from the NEDL; Vegada BN, et al, have established a similar pattern in their study. ${ }^{12}$

The trend in the present study showed that physicians preferred prescribing monotherapy more than fixed dose combination drugs. The percentages of FDC's were as low as $5.16 \%$. The resistant and relapse cases were commonly the ones that were given FDC's; while the less severe and newer cases were managed by monotherapy. Various other studies suggest a similar pattern, where the use of FDCs is comparatively lesser than monotherapy. ${ }^{12,13}$

There were no encounters with antibiotics. Primarily Antifungal drugs, steroids, anti-hitaminics were used, drugs like glycolic acid and kojic acid was also prescribed. Azoles were the most commonly prescribed anti-fungal drug group followed closely by the Allylamines; in Azoles, Imidazoles $(53.33 \%)$ were the ones more often recommended.

In this study it has been recorded that the most commonly prescribed oral anti fungal agent has been Terbinafine and the commonly given topical agent has been Eberconazole. While some other studies have mentioned Fluconazole to be the more common drug that is used. Bhagwati $\mathrm{D}$ et al and Pathak A et al in 2016 have concluded a similar prescribing pattern in Tertiary care hospitals. ${ }^{13,14}$ 
The dosage form most frequently encountered was tablet (59.61\%) followed closely by creams $(31.41 \%)$, powder $(3.2 \%)$, lotion $(2.56 \%)$, soap $(1.92 \%)$ and gel $(1.28 \%)$. Pathak A et al have come up with comparable results too. ${ }^{14}$

Self -medication has become a common health care practise among the population. The rise of this trend is because; people have become increasingly aware of the drugs and their brand names. The easy Over the Counter availability of these drugs has only given more impetus to this growing issue. This problem, although varies through different parameters viz. socio economic background of the patient, social and medical awareness, compliance of the patient, etc. The drug sensitive fungal pathogens have gradually developed resistance thus making it progressively grim to treat even the most modest fungal infections. The prevalence of self-medication for dermatological conditions among patients was found to be $62.26 \%$. Other studies have recorded self-medication practices as high as $73.6 \%-92.8 \% .^{2,3}$ Most of the drugs used for self-medication were topical (creams) FDC of antifungal and steroids. It has been documented that injudicious use of Steroidal creams has resulted into the worsening of the existing lesions and making it difficult to treat them. $78.12 \%$ of the information regarding the drugs for self-medication was obtained from the chemists.

\section{CONCLUSION}

To conclude, the study documented physician preference for Monotherapy than FDC. Prescribers need to be made aware for prescribing generic and essential drugs, thus ensuring more rational utilization of drugs. They also need to counsel and discourage patients from self-medication which is increasingly posing as a huge health hazard.

\section{ACKNOWLEDGEMENTS}

Authors would like to thank Dr. Hemangi Jerajani, HOD of Dermatology Department.

Funding: No funding sources Conflict of interest: None declared

Ethical approval: The study was approved by the Institutional Ethics Committee (No: 2016/10/10)

\section{REFERENCES}

1. De Pauw BE. What Are Fungal Infections Mediterr $\mathbf{J}$ Hematol Infect Dis. 2011;3(1):e2011001.

2. Munir M, Berg M. Emerging and Re-emerging Infectious Diseases in Developing Countries. Transbound Emerg Dis. 2013;60(4):384.

3. Pfaller MA, Diekema DJ. Rare and Emerging Opportunistic Fungal Pathogens: Concern for
Resistance beyond Candida albicans and Aspergillusfumigatus. J Clin Microbiol. 2004;42(10):4419-31.

4. Bennadi D. Self-medication: A current challenge. J Basic Clin Pharm. 2013;5(1):19-23.

5. Selvaraj K, Kumar SG, Ramalingam A. Prevalence of self-medication practices and its associated factors in Urban Puducherry, India. Perspect Clin Res. 2014;5(1):32-6.

6. Sultana F, Rahman A, Paul TP, Sarwar S, Islam AU, Rashid M. Prescribing pattern and prescription errors: a study at a tertiary care hospital of Bangladesh. Bangladesh Pharmaceutical Journal. 2015;18(1):20-4.

7. Keche Y, Yegnanarayan R, Bhoyar S, Agrawal R, Chavan R, Mahendrakar P. Self medication pattern in rural areas in Pune, India. International Journal of Medicine and Public Health. 2012;2(4):7-11.

8. Al Balushi KA, Alzaabi MA, Alghafri F. Prescribing Pattern of Antifungal Medications at a Tertiary Care Hospital in Oman. J Clin Diagn Res. 2016;10(12):FC27-30.

9. Kumar V, Mangal A, Yadav G, Raut D, Singh S. Prevalence and pattern of self-medication practices in an urban area of Delhi, India. Med J DY Patil Univ. 2015;8:16-20.

10. Tripathy S. Rising prevalence of dermatophytosis in India: A matter of concern. Journal of Infectious Diseases. 2016;45(S1):318.

11. Tyagi S, Oberoi A, Alexander V, Mohan S. Changing trends: an overview of increasing burden of fungal infections from a tertiary care hospital in Punjab (north India). International Journal of Basic and Applied Sciences. 2014;3(1):26-9.

12. Vegada BN, Karelia BN, Singh AP. Drug Utilization Study of Antifungal Agents Used in Department of Skin \& V.D. of a Tertiary Care Teaching HospitalInternational Journal of Pharmaceutical Sciences Review and Research. 2015;34(1);118-21.

13. Bhagawati I, Pathak P. A Study on Drug Utilization Pattern in Dermatology Outpatient Department in a Tertiary Care Teaching Hospital Of North East India. Journal of Medical Science and Clinical Research 2016;4(8):11857-61.

14. Pathak AK, Kumar S, Kumar M, Mohan L, Dikshit H. Study of Drug Utilization Pattern for Skin Diseases in Dermatology OPD of an Indian Tertiary Care Hospital - A Prescription Survey. J Clin Diagn Res. 2016;10(2):FC01-5.

Cite this article as: Deb P, Mohanty I, Slathia I, Verma V. Drug utilisation and self medication pattern of anti-fungal drugs in dermatology outpatient department of a tertiary care hospital. Int J Basic Clin Pharmacol 2017;6:2189-92. 